\title{
A organização e estruturação do serviço de saúde na APS para o enfretamento da Covid-19: relato de experiência
}

Silvana Carloto Andres, Auro Braz Carlotto, Andressa Leão.

\section{RESUMO}

Este artigo ter por objetivo apresentar ações e estratégias desenvolvidas pela Atenção Primária à Saúde para o enfretamento da pandemia do COVID-19 em município de pequeno porte no interior do Rio Grande do Sul. Utilizou-se da metodologia de relato de experiência baseados nas vivências e experiências dos profissionais na criação de protocolos restruturação e reorganização da unidade para a demanda de usuários com sintomas respiratórios

Palavras-chave: COVID-19; Pandemias; Atenção Primária à Saúde, Sistema Único de Saúde

\section{ABSTRACT}

This article aims to present actions and strategies developed by Primary Health Care to face the COVID-19 pandemic in a small city in the interior of Rio Grande do Sul. We used the experience reporting methodology based on experiences and professionals' experiences in creating protocols for restructuring and reorganizing the unit for the demand of users with respiratory symptoms.

Keywords: COVID-19; Pandemics; Primary Health Care, Unified Health System
Revista da Rede APS 2021

Publicada em: 01/04/2021

DOI:10.14295/aps.v3i1.137

Silvana Carloto Andres (Universidade Federal de Santa Maria, Santa Maria, RS, Brasil)

Auro Braz Carlotto (Secretaria Municipal de Saúde de Jari, Jari, RS, Brasil)

Andressa Leão

(Secretaria Municipal de Saúde de Jari, Jari, RS, Brasil)

Correspondência para:

Silvana Carloto Andres silvana.andres@yahoo.com.br 


\section{INTRODUÇÃO}

A Covid-19, é uma doença causada pelo coronavírus trata-se de uma nova cepa da família Coronaviridae (Sars-Cov-2) que foi identificada pela primeira vez na China, em dezembro de 2019, cujo alto poder de transmissão propiciou um rápido avanço para todos os continentes nos meses seguintes, o que levou a Organização Mundial de Saúde (OMS) em 30 de janeiro de 2020 a declarar estado de pandemia da COVID-19, constituindose uma Emergência de Saúde Pública de Importância Internacional e, em 11 de março de 2020, oficialmente uma pandemia (OLIVEIRA, 2020). Atualmente o Brasil, em um ano o Covid19 , já possuiu variantes na mutação viral.

Estima-se que cerca de $80 \%$ dos casos da Covid19 se manifestam de forma leve e moderada e podem ser manejados na Atenção Primária à Saúde (APS). Sendo que esse nível de atenção é capaz de exercer a contenção da transmissibilidade do COVID-19, ao minimizar a ida de pessoas com sintomas leves aos serviços hospitalares, causando sobre carga nos serviços de saúde de atenção secundária, assim a APS, atua na identificação precoce de casos com síndrome gripal e, no manejo adequado das mesmas, potencializando as ações de cuidado longitudinal aos cidadãos, além da coordenação e articulações em redes das ações entre os demais níveis de atenção da Rede da Atenção à Saúde (BRASIL,2020).

Assim, com as mudanças trazidas pela COVID19, a APS, precisou garantir o acesso à saúde e uma cobertura da população do território de forma integral e equânime (BRASIL, 2020). Esse nível de atenção do Sistema Único de Saúde (SUS) tem eficiência comprovada e se caracteriza pelo principal contato; integralidade ou abrangência; coordenação do cuidado; centralidade na família; orientação para a comunidade e prevenção de doenças principalmente com o esquema de vacinações (FERNANDEZ, 2020).

Neste contexto a APS, precisa ser reconhecida pelas suas peculiaridades e necessidades para a prática do cuidado, assim é primordial de forma rápida e lúcida se debruçar sobre os desafios postos à APS com relação às demandas da COVID19, garantindo investimentos financeiros e capacitação necessárias, em recursos humanos e materiais para que atuem de forma técnica, científica, digna e humanitária e eficiente (BARBOSA; SILVA, 2020).

O COVID19 implicou na APS a exigência de medidas efetivas de controle de infecção com consequente elaboração de protocolos, fluxogramas e notas técnicas para orientar as ações dos serviços para os profissionais de saúde e comunidade, além de prover o distanciamento necessário, garantindo os atendimentos de gestantes, crianças, idosos, vacinação e medicação de forma segura e eficaz, evitando que os usuários fiquem desassistidos e recebam um acompanhamento de qualidade, possibilitando que a equipe médica e de enfermagem receba uma demanda qualificada mesmo diante da pandemia (RODRIGUES, 2020).

Frente aos desafios postos pela pandemia, foi necessário remodelar toda a estrutura física e de recursos humanos na APS para poder prestar a melhor assistência aos usuários com sintomas respiratórios e também para os demais usuários portadores de doenças crônicas e agudas. Portanto, este artigo visa relatar a experiência e vivências dos profissionais de saúde na reorganização e restruturação do processo de trabalho da APS tendo em vista a pandemia da COVID-19.

\section{MÉTODO}

Trata-se de um estudo do tipo relato de experiência da reorganização da APS do município de Jari localizado no interior do Estado do Rio Grande do Sul. O município possui uma população de aproximadamente 3.503 pessoas, com extensão territorial de 856,475 $\mathrm{km}^{2}$, densidade demográfica de $4,17 \mathrm{hab} / \mathrm{km}^{2} \mathrm{e}$ Índice de Desenvolvimento Humano (IDH) 0,631 . Apresenta $10 \%$ de domicílios com esgotamento sanitário adequado, $91.1 \%$ de domicílios urbanos em vias públicas com arborização e $2.3 \%$ de domicílios urbanos em vias públicas com urbanização adequada 
(presença de bueiro, calçada, pavimentação e meio-fio). Quando comparado com os outros municípios do estado, fica na posição 457 de 497, 160 de 497 e 444 de 497, respectivamente. Já quando comparado a outras cidades do Brasil, sua posição é 4352 de 5570, 1393 de 5570 e 4014 de 5570, respectivamente (IBGE, 2020).

No município não existe serviço hospitalar, sendo assim quando necessário a internação de um paciente, o mesmo é transferido ao hospital de referência com encaminhamento médico e contato prévio ao serviço. O município possui um serviço de saúde com equipes de saúde interligadas entre: Equipe de Saúde da Família Núcleo de Apoio à Saúde da Família (NASF). A estrutura humana conta: com três médicos clínicos, três enfermeiros, 3 técnicos de enfermagem, 1 auxiliar de enfermagem, esses profissionais atuam no atendimento e acolhimento da equipe de enfermagem, triagem e consultas médicas e de enfermagem, possui ainda um espaço para atendimento de emergência, e ala de observação contendo dois leitos.

Os demais espaços da unidade de saúde contém farmácia básica, sala de vacinas, sala de curativos, sala para triagem e consultórios médicos, sala de atendimento de enfermagem e recepção.

O relato foi baseado na experiência desde o início das atividades instaladas no APS em março de 2020. E os dados aqui relatados são baseados nos documentos oficiais produzidos pelo município como o Plano de Contingência, protocolos de atendimentos, informativos, boletim epidemiológicos, fluxos de atendimento da rede e no relato da gestão do município.

\section{RESULTADOS}

Em fevereiro de 2020 foi confirmado o primeiro caso de COVID-19 no país, o município instituiu a restruturação de consultório respiratório em março de 2020, mesmo não havendo casos positivos no município, visando promover atendimento precoce de possíveis casos de COVID-19. Também foi elaborado o Plano de
Contingência Municipal, no qual foram definidos os níveis de resposta e os setores envolvidos na organização e fluxo de atendimento para o enfrentamento da COVID-19. Bem como, protocolos para testagens de profissionais e readequação dos atendimentos de pacientes de modo geral.

A reorganização e reestruturação da APS, teve como principais objetivos: identificar precocemente casos suspeitos; utilização de máscara cirúrgica por todos os pacientes desde o momento na triagem; todos os profissionais utilizando EPI nos atendimentos e EPIs como máscara N95, macacão descartáveis, viseira de proteção e nas exposições por um tempo mais prolongado e procedimentos que gerem aerolização; eventualmente máscara cirúrgica em exposições eventuais de baixo risco; protetor ocular ou protetor de face; luvas; capote/avental); realizar higiene de mãos, respeitando os cinco momentos de higienização, limpeza de superfícies com álcool 70\% e limpeza terminal após atendimento de casos positivos.

As estratégias visam proporcionar a ampliação do acesso dos sintomáticos respiratórios leves e moderados, manutenção do cuidado dos doentes crônicos, fortalecimento da rede de testagem ampliada dos sintomáticos, estratégias de medidas de precaução comunitária e de proteção dos profissionais.

\section{DISCUSSÕES}

\section{DO INÍCIO DA PANDEMIA A REORGANIZAÇÃO REESTRUTURAÇÃO FÍSICA DA UNIDADE DE SAÚDE}

Para se enfrentar uma doença que se propaga muito rapidamente, e não apenas acomete as pessoas, mas compromete o sistema de saúde e a sociedade como um todo, medidas preventivas individuais não são suficientes, e adicionalmente devem ser adotadas medidas de alcance comunitário (OLIVEIRA, 2020). Após a proporção do aumento de casos de COVID-19 no mundo acompanhado pelos documentos oficiais da OMS e informações da ONU, o serviço de saúde do município elaborou 
inicialmente um plano de contingência municipal, onde apresentou-se ações de enfretamento a COVID-19 de acordo com sua realidade e seu público alvo de atendimento (RIBEIRO, 2020).

Neste momento inicial a APS, também redividiu as equipes de saúde para melhor atendimento e fluxo da unidade. Umas das ações incentivada foi organização de um grupo de profissionais da saúde com a responsabilidade técnica, equipe está que fica responsável pela atualização e elaboração de novos protocolos, reorganizando conforme o andamento da pandemia na esfera local.

Também desse momento, reestruturou uma parte física da unidade de saúde para melhor atendimento de pacientes com queixas respiratórias, separadas dos atendimentos dos usuários com queixas clínicas.

\section{ORGANIZAÇÃO DO FLUXO ASSISTENCIAL PARA ATENDIMENTO NA APS}

Durante a pandemia, a APS separou usuários com sintomas respiratórios na porta de entrada do serviço, com um profissional técnico de enfermagem que trabalha na pré-recepção recebendo as pessoas que procuram a unidade de saúde, este profissional é essencial para organizar a porta de entrada, direcionando o fluxo dos pacientes.

A pré-recepção durante a pandemia vem buscando identificar desde a entrada pessoas com sintomas respiratórios. Esse profissional questiona os usuários sobre as queixas que os trouxeram até a APS, e dependendo das respostas, cada usuário pode ser direcionado para uma de duas das portas de triagem: os usuários sem sintomas respiratórios dirigem-se para triagem clínica onde são recebidos por um profissional enfermeiro, e os usuários com sintomas dirigem-se para um local separado, intitulado como consultório de doenças respiratórias, onde são atendidos por um profissional de enfermagem e médico. Neste espaço os usuários são orientados sobre etiqueta respiratória e higienização das mãos, e instruídos a manterem distanciamento e isolamento social, esses usuários não permanecem na unidade tempo além do suficiente para ser atendidos. Este atendimento envolve uma avaliação, testagem para definir se o paciente apresenta um caso leve gripal, ou um caso de COVID-19.

\section{A AQUISIÇÃO DE INSUMOS PARA CONTROLE E PREVENÇÃO DO COVID19}

Os insumos para controle e prevenção, os Equipamentos de Proteção Individual (EPI), foi um grande desafio de todos os serviços de saúde no início da pandemia da COVID-19. O medo do contágio levou à explosão do consumo de EPI além da grande dificuldade em encontrar fornecedores, além do aumento dos preços dos mesmos. A gestão municipal em conjunto com os profissionais de saúde desenvolveu um planejamento para a aquisição dos insumos de forma transparente, ágil e dentro da legislação.

A APS baseou-se nas normas e notas técnicas do Ministério da Saúde sobre as orientações de uso de EPI que regulamentou o uso racional explicitando em cada local, como, qual EPI e quando deveriam ser distribuídos e utilizados, garantindo a segurança dos profissionais $\mathrm{e}$ usuários. Neste período todos os profissionais já haviam recebido treinamento sobre paramentação e desparamentação. Em conjunto com este processo, foi criada um check list de entrada e saída de EPIs para controle de estoque garantindo insumos necessários a todos os profissionais de saúde da APS.

\section{TESTAGEM E VACINAÇÃO DE PROFISSIONAIS DE SAÚDE}

Na realização de suas atividades, os profissionais dos serviços de saúde estão exposto a vários riscos, entre eles, o de serem infectados pelo novo coronavírus (SARS-CoV-2), e do estresse associado a prestação de assistência direta aos 
pacientes suspeitos ou confirmados de COVID19. (BRASIL, 2020).

Assim como houve um esforço para adquirir mais EPI, também foi preciso replanejar os cuidados com os profissionais de saúde, visando o não adoecimento desses. De acordo com a ANVISA, os testes rápidos são de fácil execução e não necessitam de outros equipamentos de apoio (como os que são usados em laboratórios), e conseguem dar resultados entre 10 e 30 minutos (BRASIL, 2020).

Os profissionais são testados sempre que apresentem sintomas respiratórios, (clínica de síndrome gripal) ainda que não cumpram todos os critérios estabelecidos de infecção, também foram afastados profissionais de saúde que estivessem em grupos de risco (maiores de 60 anos ou com alguma morbidade de risco).

O serviço acolhe, notifica e realiza a coleta para teste rápido e posteriormente testes rápidos com punção digital - ANTICORPO ou SwabANTIGENO o qual demora alguns minutos para liberar o resultado, realizados na própria APS. Se esse profissional positivar será realizado o teste RT-PCR que geralmente utilizam secreções respiratórias, coletadas por meio de swabs de orofaringe (garganta) ou nasofaringe (nariz). São realizados em laboratórios clínicos e podem levar alguns dias para emissão de laudo (BRASIL, 2020).

Caso o profissional seja positivo, o mesmo é afastado de suas atividades, e seus contactes e familiares são monitorados e possivelmente testados. Caso os familiares apresentem resultados positivos a testagem segue até encontrar o contactante negativo.

Todos os profissionais testados são incluídos no sistema e-SUS notifica, e possui laudo impresso emitido pelo profissional que realizou o teste.

A vacinação seguirá todas as normas de etapas do MS, conforme recebimento de dosagens, visando a prevenção e ação de barrar a expansão do COVID-19.

\section{TESTAGEM DOMICILIAR PARA \\ SINTOMÁTICOS RESPIRATÓRIOS}

Foi montada uma equipe técnica treinada composta por profissionais de saúde, sendo assim uma equipe multiprofissional, com todos profissionais capacitados para a realização do teste rápido. Todos os usuários que estão sendo monitoradas, independentemente da gravidade dos sintomas, são testados.

Alguns casos confirmados ou suspeitos de COVID-19 podem não necessitar de hospitalização, devendo ser acompanhados em domicílio. Porém, é necessário avaliar cada caso, levando-se em consideração se o ambiente residencial é adequado e se o paciente é capaz de seguir as medidas de precaução recomendadas pela equipe de saúde $\mathrm{O}$ apoio fundamental para responder a necessidade de ampliar a rede de diagnóstico e de controle da COVID-19.

\section{CONSIDERAÇÕES FINAIS}

Diante do exposto, neste relato de experiência, consideramos que a reestruturação imediata do fluxo de trabalho dos profissionais da APS no município de Jari, desde o início da pandemia, foi de extrema importância para que no momento atual continuemos entre os poucos municípios do Rio Grande do Sul com zero casos de COVID-19 até a data do envio deste artigo. Permitindo ao serviço continuar a atender a demanda clínica e as rotinas e, de maneira diferencial, as síndromes gripais, considerando que a Unidade Básica de Saúde é a primeira e única forma de acesso dos usuários aos serviços de saúde no município.

O empenho e comprometimento de cada profissional, bem como a facilidade em se adaptar as novas rotinas de trabalho impostas pela pandemia, uso de EPI e novos protocolos e diretrizes, destacam-se como um dos principais pontos para a boa atuação da APS no enfrentamento ao Covid 19.

Por fim, a APS precisou assumir com urgência o protagonismo como ordenadora do cuidado no SUS frente a pandemia, buscando a cada dia se adaptar a novas rotinas e protocolos que mudam constantemente. $O$ sucesso do 
APS em Revista

Vol. 3, n. 1, p. 09-15 | Janeiro/Abril - 2021

ARTIGOS

ISSN 2596-3317-DOI 10.14295/aps.v3i1.137

Andres, S. C.; Carlotto, A. B.; Leão, A.

enfrentamento à Covid 19 e o futuro do Sistema Único de Saúde depende de cada um de nós, gestores, profissionais e usuários. 


\section{REFERÊNCIAS}

BARBOSA, S.; SILVA, A.V. A Prática da Atenção Primária à Saúde no Combate da COVID-19. APS em Revista. Belo Horizonte, v. 2, n. 1, p. 17-19, 2020

BRASIL. NOTA TÉCNICA № 20/2020-DESF/SAPS/MS. Ministério da Saúde Secretaria de Atenção Primária à Saúde Departamento de Saúde da Família. 2020.

BRASIL, Agência Nacional de vigilância Sanitária. Testes para Covid-19: perguntas e respostas. 2020. Acesso: $[01$ jul de 2020]. Disponível em: http://portal.anvisa.gov.br/documents/219201/4340788/Perguntas+e+respostas+-+testes+para+Covid19.pdf/9fe182c3-859b-475f-ac9f-7d2a758e48e7

FERNANDEZ, M. V.; CASTRO, D. M.; FERNANDES, L. M. M.; ALVES, I. C. Reorganizar para avançar: a experiência da Atenção Primária à Saúde de Nova Lima/MG no enfrentamento da pandemia da COVID-19. APS em Revista. Vol. 2, n. 2, p. 114-121| Junho-2020ISSN 2596-3317 -DOI 10.14295/aps.v2i2.84.

OLIVEIRA, K.W.; DUARTE, E.; FRANÇA, G.V.A.; GARCIA, F.L. Como o Brasil pode deter a COVID-19. Epidemiologia. Serviços de Saúde, Brasília, 29(2):e2020044, 2020. Acesso em: [ jun 30 de 2020]. Disponível em: https://www.scielosp.org/article/ress/2020.v29n2/e2020044/pt/

RODRIGUES, A. P. Telemonitoramento como estratégia de cuidado longitudinal a grupos prioritários em tempos da COVID-19: uma experiência na atenção primária à saúde do município de Vitória-ES.

RIBEIRO, M. A.; JUNIOR, D. G. A.; CAVALCANTE, A. S. P.; MARTINS, A. F.; SOUSA, L. A.; CARVALHO, R. C.; CUNHA, I. C. K. O (RE)Organização da Atenção Primária à Saúde para o enfrentamento da COVID-19: Experiência de Sobral-CE. APS em Revista. Vol. 2, n. 2, p. 177-188| Junho-2020ISSN 2596-3317 -DOI 10.14295/aps.v2i2.125. 